\title{
Understanding inflammatory residual risk sheds new light on clinical importance of periodontitis in cardiovascular disease.
}

\author{
Marta Czesnikiewicz-Guzik BDS PhD; Francesco D’Aiuto DMD PhD, John E Deanfield MD PhD
}

Understanding of the role of inflammation in mediating cardiovascular risk has been questioned by the recent publication of the CANTOS Trial ${ }^{1}$. This fairly large proof of concept study showed for the first time that targeting body chronic inflammation is linked to reduced cardiovascular events particularly in patients with high residual inflammatory risk as identified by high hsCRP and high IL- 6 levels. Whilst the study demonstrated that harnessing upstream inflammation can prevent cardiovascular events, discussion continues on ways to safely target inflammation ${ }^{2}$. Notwithstanding pharmacological approaches are clearly feasible, identifying and treating unconventional but common sources of systemic inflammation, causally associated to cardiovascular diseases creates a unique, safe and cheap opportunity. Interestingly, periodontitis represents one the most prevalent form of chronic inflammatory disease (both local and systemic) worldwide with an estimated frequency of $40-70 \%{ }^{3}$. Most of recent surveillance surveys estimate that at least $40 \%$ of dentate adults 30 years or older have some form of periodontitis and these figures reaching $>60 \%$ in people over 65 (REF).

Until recently the vast majority of evidence available linking periodontitis to cardiovascular diseases was mainly derived from observational or based on small underpowered studies ${ }^{3}$. In some of these studies surrogates were used to reason about the periodontal status such as presence of loose teeth or poor oral hygiene. In 2012, the American Academy of Periodontology issued a joined statement with the American Heart Association about the link between cardiovascular diseases and periodontal diseases: "Observational studies to date support an association between PD and ASVD independent of known confounders. They do not, however, support a causative relationship. ${ }^{4,5}$.

Over the last 10 years, promising evidence resulting from randomized clinical trials demonstrate that intensive treatment of periodontitis can affect cardiovascular risk. In a landmark study it was shown that a single session of intensive dental treatment to manage periodontal inflammation caused an initial deterioration but then a steady improvement in a surrogate measure of vascular function. Systematic appraisal of the evidence from small intervention studies which followed confirmed that treatment of periodontitis produced a reduction of systemic inflammation especially in patients with other comorbidities (i.e. diabetes) (Teew et al..) and that both endothelial function and surrogate measures of atheroma (cIMT) were improved (Orlandi et al 2014). On this basis, it is not surprising to report that a recent randomized clinical trial demonstrated that managing effectively periodontal inflammation was associated with improved metabolic status in patients with type 2 diabetes up to 12 months. This benefit was linked to a progressive reduction of systemic inflammation (as assessed by CRP and TNF- $\alpha$ ) and more interestingly to an improved vascular and kidney functions profiles of patients in the test group (D'Aiuto et a 2018). These changes were independent of common cardio-vascular risk factors and even of standard pharmacologic regimens to tackle the well-known residual vascular risk of patients with diabetes. 
An important and often underestimated insight of this study is that the degree of improvement in metabolic and vascular parameters was mostly associated in a linear fashion with the magnitude of reduction of gingival inflammation and improved oral health (alluding at the obvious bacterial and inflammatory burden represented at the dento-gingival interface). Direct microbial distant effects on the vascular system have been previously postulated through interactions of circulating bacteria with endothelium ${ }^{6}$. Additionally, there is lack of compelling evidence that periodontal bacteria found in the atherosclerotic plaque by PCR are viable ${ }^{7}$. At the same time many authors demonstrated systemic activation of the immune system in process of periodontitis by showing elevation of the production of proinflammatory markers and cytokines ${ }^{8-13}$. Consistent evidence demonstrates a significant decrease of proinflammatory cytokines and improvement of endothelial function after intensive periodontal treatment ${ }^{14}$. Following this study other groups confirmed a beneficial influence of periodontal treatment on inflammatory markers as cytokines, CRP and endothelial function 10,11,15-18. It is also worth highlighting that rather than just a mere reduction of biomarkers of inflammation, recent evidence points at cellular pathways linked to vascular reactivity as exciting new mechanisms through which common sources of extravasal inflammation could influence the onset and progression of vascular disease (Masi et al 2018).

We have recently extended this understanding to hypertension and blood pressure control. So far, similarly to other CVD, the evidence linking periodontitis and hypertension was purely based on observational evidence ${ }^{13,14,19-28}$, which we have recently systematically appraised and confirmed that diagnosis of periodontitis is associated with an average $20 \%$ increase of hypertension risk and an average increase of blood pressure of moderate magnitude ( range in $\mathrm{SBP}=113-172 / \mathrm{DBP}=66-101 \mathrm{mmHg})^{29}$. Further exploring this link, a Mendelian Randomization in the UK-Biobank and ICBP-GWAS datasets (including 750,000 participants) was undertaken to determine the causal nature of the relationship of periodontitis with increased blood pressure using previously GWAS-linked genetic variants as surrogates of lifetime risk of periodontitis. The same group performed the first randomized trial using ambulatory blood pressure as a primary endpoint in patients with insufficiently controlled hypertension. 101 patients with office blood pressure $>140 / 90 \mathrm{mmHg}$ despite stable antihypertensive regimen (using at least 1 medication for over 6 months) and concomitant moderate to severe periodontitis were randomized $1: 1$, to receive intensive or control periodontal treatment. In the intensive therapy group, 2-months after treatment we observed a reduction in blood pressure of $7.5+/-10.5 \mathrm{mmHg}$. This was accompanied by improved endothelial function as assessed by flow mediated dilatation. It was reassuring to note that the degree of SBP reduction was again mainly correlated with the improvement of gingival inflammation. These findings raise the question of whether improving periodontal health could result in substantial blood pressure reductions in larger populations and more importantly without changes of standard pharmacotherapy. Whilst the degree of blood pressure reduction may appear large, it is important to note that it is consistent with the results of few intervention trials using office blood pressure after periodontitis treatment. In the most recent of these randomized trials, the change in blooed pressure between intensive and control periodontal therapy reached $12,57+/-10.4 \mathrm{mmHg}$ when measured in patients with prehypertension ${ }^{30}$.

Pathomechanisms of the effects of periodontitis on vascular blood pressure regulation are complex and not fully understood but they link into recently discovered immune mechanisms 
underlying hypertension ${ }^{31}$. It has been demonstrated that periodontal inflammation is not only local process confined within the periodontal tissue but periodontal microbial antigens are leading to activation of innate and adaptive immunity. These activated cells can easily contribute to developing pathology in the vessels wall, kidney and penetrate blood-brain barrier to influence sympathetic nervous system ${ }^{32}$.

Similar mechanisms are likely to link periodontitis to hypertension. In a recent experimental model of hypertension, immunization of mice using $P$. gingivalis antigens caused increased susceptibility to raised blood pressure in response to sub-pressor doses of Angiotensin II ${ }^{33}$. In the recently reported clinical trial, analysis of pro- and anti-inflammatory cytokines and circulating cell immunophenotyping has demonstrated significant reductions in circulating IFN-gamma, IL-17, IL-6 levels in plasma as well as pro-inflammatory monocytes (CD16+CD14dim) and activated CD8+CD38+ T cells after 2 months after intensive periodontal therapy ${ }^{34}$ suggesting that these cells may be linked to pathogenesis of periodontitis, while their role in hypertension has also been shown before.

In summary, recent eveidence has changed our understanding of the relationship between cardiovascular risk and periodontitis. Initially thought to be observational and coincidental, it is now evident that periodontal health could be an essential parameter for vascular function, glucose control, metabolic health and blood pressure control as well. Considering the high prevalence in the general population, the research community should face the possibility that periodontitis is one of the key contributors to body chronic inflammation hence it can be a major contributor to a residual inflammatory burden/risk.

\section{References:}

1. Ridker PM, Everett BM, Thuren T, MacFadyen JG, Chang WH, Ballantyne C, Fonseca F, Nicolau J, Koenig W, Anker SD, Kastelein JJP, Cornel JH, Pais P, Pella D, Genest J, Cifkova R, Lorenzatti A, Forster T, Kobalava Z, Vida-Simiti L, Flather M, Shimokawa H, Ogawa H, Dellborg M, Rossi PRF, Troquay RPT, Libby P, Glynn RJ, Group CT. Antiinflammatory Therapy with Canakinumab for Atherosclerotic Disease. N Engl J Med 2017;377(12):1119-1131.

2. Maffia P, Guzik TJ. When, where, and how to target vascular inflammation in the postCANTOS era? Eur Heart J 2019;40(30):2492-2494.

3. Tsioufis C, Kasiakogias A, Thomopoulos C, Stefanadis C. Periodontitis and blood pressure: the concept of dental hypertension. Atherosclerosis 2011;219(1):1-9.

4. Lockhart PB, Bolger AF, Papapanou PN, Osinbowale O, Trevisan M, Levison ME, Taubert KA, Newburger JW, Gornik HL, Gewitz MH, Wilson WR, Smith SC, Jr., Baddour LM, American Heart Association Rheumatic Fever E, Kawasaki Disease Committee of the Council on Cardiovascular Disease in the Young CoE, Prevention CoPVD, Council on Clinical C. Periodontal disease and atherosclerotic vascular disease: does the evidence support an independent association?: a scientific statement from the American Heart Association. Circulation 2012;125(20):2520-44.

5. Tonetti MS, Van Dyke TE, working group 1 of the joint EFPAAPw. Periodontitis and atherosclerotic cardiovascular disease: consensus report of the Joint EFP/AAP Workshop on Periodontitis and Systemic Diseases. Journal of Periodontology 2013;84(4 SuppI):S24-9. 
6. Angeli F, Verdecchia P, Pellegrino C, Pellegrino RG, Pellegrino G, Prosciutti L, Giannoni C, Cianetti S, Bentivoglio M. Association between periodontal disease and left ventricle mass in essential hypertension. Hypertension 2003;41(3):488-92.

7. Ahn YB, Shin MS, Byun JS, Kim HD. The association of hypertension with periodontitis is highlighted in female adults: results from the Fourth Korea National Health and Nutrition Examination Survey. J Clin Periodontol 2015;42(11):998-1005.

8. D'Aiuto F, Sabbah W, Netuveli G, Donos N, Hingorani AD, Deanfield J, Tsakos G. Association of the metabolic syndrome with severe periodontitis in a large U.S. populationbased survey. Journal of Clinical Endocrinology \& Metabolism 2008;93(10):3989-94.

9. Holmlund A, Holm G, Lind L. Severity of periodontal disease and number of remaining teeth are related to the prevalence of myocardial infarction and hypertension in a study based on 4,254 subjects. Journal of Periodontology 2006;77(7):1173-8.

10. Tonetti MS, D'Aiuto F, Nibali L, Donald A, Storry C, Parkar M, Suvan J, Hingorani AD, Vallance $P$, Deanfield J. Treatment of periodontitis and endothelial function. $N$ Engl J Med 2007;356(9):911-20.

11. Raffaelli L, Santangelo R, Falchetti P, Galluccio F, Luciani N, Anselmi A, Nowzari H, Verdugo $F$, Fadda $G$, D'Addona A. Examination of periodontal pathogens in stenotic valve specimens and in whole blood samples in patients affected by aortic valve stenosis and chronic periodontitis. International Journal of Immunopathology \& Pharmacology 2010;23(2):561-6.

12. Marjanovic M, Buhlin K. Periodontal and systemic diseases among Swedish dental school patients - a retrospective register study. Oral Health \& Preventive Dentistry 2013;11(1):49-55.

13. Hansen GM, Egeberg A, Holmstrup P, Hansen PR. Relation of Periodontitis to Risk of Cardiovascular and All-Cause Mortality (from a Danish Nationwide Cohort Study). Am J Cardiol 2016.

14. Morita T, Yamazaki Y, Fujiharu C, Ishii T, Seto M, Nishinoue N, Sasaki Y, Nakai K, Tanaka $\mathrm{H}$, Kawato T, Maeno M. Association Between the Duration of Periodontitis and Increased Cardiometabolic Risk Factors: A 9-Year Cohort Study. Metabolic Syndrome \& Related Disorders 2016;14(10):475-482.

15. Zeigler CC, Wondimu B, Marcus C, Modeer T. Pathological periodontal pockets are associated with raised diastolic blood pressure in obese adolescents. BMC Oral Health 2015;15:41.

16. Schmitt A, Carra MC, Boutouyrie P, Bouchard P. Periodontitis and arterial stiffness: a systematic review and meta-analysis. J Clin Periodontol 2015;42(11):977-87.

17. Ramirez JH, Parra B, Gutierrez S, Arce RM, Jaramillo A, Ariza Y, Contreras A. Biomarkers of cardiovascular disease are increased in untreated chronic periodontitis: a case control study.[Erratum appears in Aust Dent J. 2015 Mar;60(1):135]. Australian Dental Journal 2014;59(1):29-36.

18. Aguilera AM, Suvan J, Buti J, Czesnikiewicz-Guzik M, Orlandi M, Guzik TJ, Hingorani AD, Nart J, F. DA. Periodontitis and its treatment are associated with Hypertension.

A systematic review and Meta-analysis. Cardiovasc Res 2019;in press.

19. Zhou QB, Xia WH, Ren J, Yu BB, Tong XZ, Chen YB, Chen S, Feng L, Dai J, Tao J, Yang JY. Effect of Intensive Periodontal Therapy on Blood Pressure and Endothelial Microparticles in Patients With Prehypertension and Periodontitis: A Randomized Controlled Trial. J Periodontol 2017;88(8):711-722. 
20. Guzik TJ, Hoch NE, Brown KA, McCann LA, Rahman A, Dikalov S, Goronzy J, Weyand C, Harrison DG. Role of the $T$ cell in the genesis of angiotensin II induced hypertension and vascular dysfunction. J Exp Med 2007;204(10):2449-60.

21. Marvar PJ, Thabet SR, Guzik TJ, Lob HE, McCann LA, Weyand C, Gordon FJ, Harrison DG. Central and peripheral mechanisms of T-lymphocyte activation and vascular inflammation produced by angiotensin II-induced hypertension. Circ Res 2010;107(2):263-70.

22. Czesnikiewicz-Guzik M, Nosalski R, Mikolajczyk TP, Vidler F, Dohnal T, Dembowska E, Graham D, Harrison DG, Guzik TJ. Th1-type immune responses to Porphyromonas gingivalis antigens exacerbate angiotensin II-dependent hypertension and vascular dysfunction. $\mathrm{Br} \mathrm{J}$ Pharmacol 2018.

23. Czesnikiewicz-Guzik M, Osmenda G, Siedlinski M, Nosalski R, Pelka P, Nowakowski $D$, Wilk G, Mikolajczyk TP, Schramm-Luc A, Furtak A, Matusik P, Koziol J, Drozdz M, MunozAguilera E, Tomaszewski M, Evangelou E, Caulfield M, Grodzicki T, D'Aiuto F, Guzik TJ. Causal association between periodontitis and hypertension: evidence from Mendelian randomization and a randomized controlled trial of non-surgical periodontal therapy. Eur Heart J 2019. 